Turkish Journal of LiDAR

Türkiye LiDAR Dergisi

https://dergipark.org.tr/tr/pub/melid

e-ISSN 2717-6797

\title{
Lazer Tarayıcının Jeolojik Olayların Modellenmesinde Kullanımı
}

\author{
Aydın ALPTEKİN ${ }^{*}$ (b), Murat YAKAR ${ }^{2}$ 툴 \\ ${ }^{1}$ Mersin Üniversitesi, Mühendislik Fakültesi, Jeoloji Mühendisliği Bölümü, Mersin, Türkiye \\ 2 Mersin Üniversitesi, Mühendislik Fakültesi, Harita Mühendisliği Bölümü, Mersin, Türkiye
}

Anahtar Kelimeler

Uzaktan Algılama,

Lazer tarayıcl,

Jeolojik olaylar.

\begin{abstract}
ÖZ
Lazer tarayıcı teknolojisi son yıllarda hızla gelişmektedir. Bu teknolojinin mühendislik çalışmalarında kullanılmaya başlanmasıyla birlikte mühendislerin işleri kolaylașmaktadır. Lazer tarayıcı verileri hızlı bir șekilde ve yüksek çözünürlükte temin edilebilmektedir. $\mathrm{Bu}$ durum lazer tarayıcıları cazip bir hale getirmektedir. Lazer tarayıcılar; arkeolojide, doğal afetlerde, erozyon izlemede ve kazı hacminin belirlenmesinde eksi yönlerini de düşünerek kullanılabilir. Arazinin üç boyutlu (3B) modeli kolay bir șekilde oluşturulabilmekte ve arazideki küçük değişimler rahatlıkla gözlenebilmektedir. Bu çalıșmada lazer tarayıcıların jeolojide kullanılabilirliği üzerinde durulacaktır. Jeolojik olayların yorumlanması, analiz edilmesi ve çözüm önerilerinin getirilmesi bu yöntemler sayesinde daha hassas ve pratik bir şekilde yapılabilmektedir.
\end{abstract}

\section{Usage of Laser Scanner in Modeling Geological Events}

\author{
Keywords \\ Remote sensing, \\ Laser scanner,
}

Geological events.

\begin{abstract}
Laser scanner technology has been developing rapidly in recent years. With the use of this technology in engineering studies, the work of engineers becomes easier. Laser scanner data will be obtained quickly and in high resolution. This makes laser scanners attractive. Laser scanners can be used in archeology, natural disasters, erosion monitoring and determination of excavation volume considering the deficiencies. A three-dimensional (3D) model of the land can be created easily and small changes in the land can be easily observed. In this study, the usability of laser scanners in geology will be emphasized. Interpretation, analysis and solution proposals of geological events can be performed more sensitively and practically with this method.
\end{abstract}




\section{GİRiş}

Uzaktan algılama tekniklerinin sürekli olarak gelişmesi yer yüzeyini modellemede bize kolaylıklar sağlamaktadır. Objelere temas etmeden onların bilgisayar ortamında üç boyutlu (3B) modellenmesi kolaylıkla yapılabilmektedir. $\mathrm{Bu}$ nedenle son yıllarda insansız hava araçları (İHA), uydu görüntüleri ve lazer tarayıcılar sıklıkla modelleme çalışmalarında kullanılmıştır.

Light Detection and Ranging (LiDAR), yüksek çözünürlük ve hassasiyette $3 \mathrm{~B}$ veri almamızı sağlayan bir tekniktir. Kaynaktan çıkan lazer ışını objeye çarpıp tekrar kaynağa gelir ve kayıt altına alınır. Arada geçen zamandan objenin uzaklığı ve geometrik yapısı belirlenir. Lazer tarayıcılar hava (HLT), yersel (YLT) ve mobil lazer tarayıcı (MLT) olmak üzere üçe ayrılmaktadır. $\mathrm{Bu}$ tarayıcılar yüksek maliyetli olmasından dolayı her yerde bulunmamaktadır. YLT zemine monte edilerek dar alanlarda, HLT ise bir hava aracına monte edilerek geniş arazinin modellenmesinde tercih edilmektedir. MLT ise daha çok kara veya deniz aracının üzerine monte edilerek kullanılmaktadır.

Lidar; lazer tarayıcl, IMU ve GPS' ten oluşan bir sistemdir (Tepeköylü, 2016). Lidar sistemleri mobil, hava, yersel ve iha lidar olmak üzere 4 ana başlık altında sinıflandırılabilir (Makineci, 2016). Obje ile lazer tarayıcı arasındaki mesafe lazer ışının süresiyle tespit edilir (Karasaka \& Beg, 2021).

Lidar verilerinin zemine ait olan ve olmayan olarak ayrılmasına filtreleme denilmektedir (Şen \& Bayash 2021). Sayısal arazi modelleme (SAM) işleminde filtreleme büyük bir öneme sahiptir. Sayısal arazi modeline etki eden faktörler; veri miktarı, enterpolasyon method ve grid aralığıdır (Navruz 2017). Yüksek nokta sıklığı sayısal arazi modeli (SAM) doğruluğunu arttırmaktadır. YLT' de nokta yoğunluğu fazladır. HLT' de veri eksikliği minimum seviyededir.

LiDAR verilerinin pek çok kullanım alanı vardır. Bu çalışmada lazer tarayıcıların jeolojik çalışmalarda kullanılması hakkında bilgiler verilecektir.

\section{JEOLOJIKK ÇALIŞMALAR}

$\mathrm{Bu}$ çalışmada lazer tarayıcı kullanarak yapılan obruk, heyelan, kaya düşmesi, fay karakterizasyonu, kıyı izleme, akarsu ağı ve arkeolojik çalışmalar hakkında bilgiler verilecektir.

\subsection{Obruk çalışmaları}

Yeraltı suyunun karbondioksitle çözünmesi sonucu oluşan karbonik asit zamanla çevresindeki kayaçlarda çözünme oluşturur ve yeraltında obruk adı verilen boşluklar oluşur. Obruklar tarım arazilerine, binalara ve yollara zarar vermektedir. Obrukların sayısı gün geçtikçe artmaktadır. Bunun başlıca sebepleri yarı kurak iklim ve bilinçsiz tarım uygulamalarıdır. Obrukların haritalandırılması bize bölgenin hidrojeolojik özelliklerini belirlemede çok faydalı olacaktır. Türkiye'de Konya İli Karapınar ilçesinde bolca obruk gözlenmektedir.

Obruk risk haritasının oluşturulabilmesi için öncelikle obruk envanter haritasının oluşturulması gerekmektedir. Obrukların haritalandırılması bölgenin hidrojeolojisinin anlaşılabilmesi için çok önemlidir.

Obruk çalışmaları geniş alanlara hitap ettiği için genellikle HLT kullanılmaktadır.

Zhu ve diğ. 2014 HLT kullanarak karstik bir arazideki obrukların envanter haritasını oluşturmuşlardır. Lidar verisinden DEM oluşturmuşlar, çöküntü havzalarının yerlerini belirlemişler, potansiyel obruk yerlerini belirlemişler ve arazide kontrolünü yapmışlardır. $\mathrm{Bu}$ şekilde 1683 adet obruk tespit etmişlerdir.

Filin ve ark. 2011 HLT kullanarak araziyi 3B olarak karakterize etmişlerdir. Oluşturulan DEM verisinden obrukların genişliğini ve derinliğini belirlemişlerdir. Ayrıca obrukları çevreleyen jeomorfolojik özellikleri ortaya çıkartmışlardır. Kobal ve diğ. 2015 HLT kullanarak ormanlık bir alandaki 2660 adet obruk tespit etmişlerdir. Obrukların morfometrik yapısını belirlemişlerdir. Obrukların her birinin uzunluk, genişlik, derinlik, alan ve hacim bilgileri hesaplanmıştır.

\subsection{Tektonik çalışmalar}

Türkiye aktif fay hatları üzerinde yer almaktadır. Fay hatlarının düzenli olarak izlenmesi olabilecek tehlikenin önlenebilmesi için çok önemlidir.

Cunningham ve ark. 2006 HLT kullanarak bir arazinin 3B modelini oluşturmuştur. Terrasolid tarafından geliştirilen bir algoritma kullanarak bitki örtüsünü kaldırmış ve yüzey modeli oluşturmuşlardır. Yüzey modeli üzerinden arazideki fay hatlarını belirlemişlerdir.

Glennie ve ark. (2014) HLT kullanarak deprem öncesi ve sonrası arazi modeli oluşturmuşlar ve 3B deplasman değerini hesaplamışlardır. Meigs 2013 HLT verisini OpenTopography programını kullanarak modellemiştir. LaDiCaoz modülünü kullanarak fayın atım miktarını belirlemişlerdir.

\subsection{Kıyı izleme}

Kıyılar, dalga ve rüzgâr erozyonuna maruz kalmaktadır. Ayrıca küresel ısınma ile birlikte deniz suyu seviyesi yükselmektedir. Bu bölgelerin düzenli olarak izlenmesi gerekmektedir.

Alptekin vd. 2020b Mersin Akyar Falezi' ni YLT kullanarak modellemişleridir. Falez karbonatlı kayaçlardan oluşmaktadır ve dalga erozyonuna maruz kalmaktadır.

\subsection{Akarsu erozyonu}

DEM verisi sayesinde akarsu drenaj ağı ve havzanın morfolojik özellikleri çıkartılabilir.

Perroy ve ark. 2010, Akarsu erozyonu belirlemek için hava ve yersel lazer tarayıcı kullanmışlar ve birbirleriyle karşılaştırmışlardır. HLT nin az çözünürlüklü ama hızlı bir yöntem olduğunu belirtmişlerdir. Cavalli ve ark. 2008 HLT kullanarak akarsu yatağındaki morfolojik değişmeleri incelemişlerdir. TerraScan yazılımı kullanarak bitki örtüsünü kaldırmışlardır. Açık kaynak kodlu TauDEM yazılımını kullanarak morfolojik parametreler tespit edilmiştir. 


\subsection{Hidrojeoloji}

Çelik ve diğ. 2014 yılında yaptıkları bir çalışmada HLT kullanarak bir taşkın sahasını modellemiştir. Arazinin SYM üretmişler ve ArcGIS' te hidrolojik modelleme yapmışlardır.

Büyüksalih ve Gazioğlu 2019 HLT kullanarak Melen Baseni' nin 3B modelini oluşturmuşlardır. DEM verisini kullanarak CBS ortamında eğim ve bakı haritaları oluşturmuşlar ve akım yönlerini belirlemişlerdir.

\subsection{Kaya düşmesi}

Kaya düşmesi, kaya kütlesinin ani bir hareketle yerinden çıkarak yer çekimi etkisiyle aşağı yönde yuvarlanması olarak tanımlanır. Dağlık alanlarda en sık görülen doğal afet olan kaya düșmesi insanlara ve yapilara zarar vermektedir.

Alptekin \& Yakar 2020a Mersin Erdemli Karahıdırlı' da bulunan bir kaya düşmesi sahasını YLT kullanarak modellemiştir.

\subsection{Heyelan}

Toprak kütleleri üzerindeki kuvvetlerin değişmesi sonucu zemin duyarlılığını yitirmektedir. Bu durumda kütle hareketi görülmekte ve zemin yamaç aşağı yönde hareket etmektedir. Hızlı ve plansız yapılaşma heyelanın görülmesinde en belirleyici unsurdur. Tektonik hareketler, aşırı yağıșlar ve kontrolsüz kazılar en belirgin tetikleyici unsurlardır.

Kasai vd. 2009 heyelan bölgesinde HLT kullanarak yüksek çözünürlüklü sayısal yüzey modeli oluşturmuşlardır.

Tseng vd. 2013 HLT kullanarak heyelan bölgesini modellemiş ve arazinin çıplak sayısal modelini (DTM) oluşturmuştur. DTM verisinden heyelanın hacmini belirlemiştir.

\subsection{JeoArkeoloji}

Kültürel mirasımızın korunması, gerektiği durumlarda restore edilmesi ve gelecek nesillere aktarılması için bilgisayar ortamında yüksek çözünürlükte modellenmesi gerekmektedir. Lazer tarayıcılar ile dakikalar içerisinde objeye temas etmeden objenin 3B modeli oluşturulabilmektedir. Böylece obje kayıt altına alınmaktadır. Tarihi eserler yıllar içerisinde insanlar ve tabiat olaylarından olumsuz etkilenmektedir. Son yıllarda jeoarkeoloji çalışmalarında YLT kullanımı yaygınlaşmıştır.

Alptekin ve diğ. 2019a Mersin Kanlıdivane' de bulunan bir anıtmezarı YLT kullanarak modellemişlerdir. Alptekin ve diğ. 2019b Mersin Erdemli'de bulunan Üçayak Harabeleri' ni YLT kullanarak modellemişlerdir. Kaya ve di $\breve{g}$. 2021 tarafından YLT kullanarak Konya ili Yunuslar Mahallesi' nde arkeolojik kazı alanının modellemesi YLT ile yapılmıştır. Yakar vd. 2014, Mersin Uzuncaburç̧'ta YLT kullanarak arkeolojik kazı alanını modellemişlerdir. Ulvi ve Yakar 2014, Mersin Kızkalesi'nde YLT kullanmışlardır.

\subsection{Arazi hacmi}

İnşaat projelerinde ve maden sektöründe projenin maliyet hesabı için kazı hacminin belirlenmesi gerekmektedir. Bunun için son yllarda LiDAR verileri kullanılmaktadır.

Yakar vd. 2009 tarafindan bir kum ocağının hacim hesabı YLT ile yüksek doğruluk oranında belirlenmiștir.

Yakar vd. 2010 tarafindan bir kazı alanının hacmi jeodezik, robotik total station ve lazer tarayıcı metotlarıyla belirlenmiş ve en doğru sonuç veren yöntemin YLT olduğu belirtilmiştir.

\section{LİDAR VERISINININ IŞLENMESI}

LiDAR verileri yoğun nokta bulutu içerdiğinden dolayı büyük hacme sahip verilerdir. Bu verilerin işlenmesi için üst düzey bilgisayarlara ihtiyaç vardır.

Son yıllarda sıklıkla kullanıldıklarından dolayı verilerin işlenebileceği programların sayısı da artmaktadır. Bunlardan en sık kullanılanları Tablo 1 de gösterilmektedir.

Tablo 1. LiDAR verisini işleyen programlar (Polat and Uysal 2016)

\begin{tabular}{ll}
\hline Ticari & Açlk kaynak kodlu \\
\hline VRMesh survey & Cloudcompare \\
LIDAR Analyst & LViz \\
LiForest & Points2Grid Utility \\
Global Mapper & BCAL LiDAR Tools \\
QTModeler & River Bathymetry Toolkit \\
TerraScan & SAGA GIS \\
Makai Voyager & DielmoOpenLidar \\
\hline
\end{tabular}

Nokta bulutunun verileri zemin ve zemin olmayan olarak gruplandırılır. Bunun için genellikle Cloth simulation filter (CSF) algoritması kullanılmaktadır. Algoritmanın detayları Karasaka ve Keleş 2020 tarafından açılanmıştır. Ayrıca QGIS programı içerisindeki lastools eklentisi ile filtreleme işlemi yapilabilmektedir.

\section{SONUÇLAR}

Son yıllarda jeolojik çalışmalarda uzaktan algılama tekniklerinden olan LiDAR yöntemi sıklıkla kullanılmıştır. Gelecekte bu yöntem daha sık kullanılacak ve pek çok jeolojik sorunun çözümüne katkıda bulunacaktır.

LiDAR verisi yüksek nokta sıklı̆̆ı içerdiğginden dolayı araziyi yüksek doğrulukta yansıtabilmektedir. Teknolojinin gelişmesiyle birlikte yakın zamanda LIDAR sistemi ekonomik bir şekilde kullanılabilecektir.

\section{Yazarların Katkısı}

Aydın Alptekin: Literatür taraması, Makale yazımı; Murat Yakar: Düzenleme

\section{Çıkar Çatışması Beyanı}

Yazarlar arasında herhangi bir çıkar çatışması bulunmamaktadır. 


\section{Araştırma ve Yayın Etiği Beyanı}

Yapılan çalışmada araştırma ve yayın etiğine uyulmuştur.

\section{KAYNAKÇA}

Alptekin A, Çelik M Ö \& Yakar M (2019a). Anıtmezarın yersel lazer tarayıcı kullanarak 3B modellenmesi. Türkiye Lidar Dergisi, 1 (1), 1-4.

Alptekin A, Fidan Ş, Karabacak A, Çelik M Ö \& Yakar M (2019b). Üçayak Örenyeri'nin yersel lazer tarayıcı kullanılarak modellenmesi. Türkiye Lidar Dergisi, 1 (1), 16-20.

Alptekin A \& Yakar M (2020a). Kaya Bloklarının 3B Nokta Bulutunun Yersel Lazer Tarayıcı Kullanarak Elde Edilmesi. Türkiye Lidar Dergisi, 2 (1), 1-4.

Alptekin A \& Yakar M (2020b). Mersin Akyar Falezi'nin 3B modeli. Türkiye Lidar Dergisi, 2(1), 5-9.

Büyüksalih İ \& Gazioğlu C (2019). New Approach in Integrated Basin Modelling: Melen Airborne LIDAR. International Journal of Environment and Geoinformatics, 6(1), 22-32.

Cavalli M, Tarolli P, Marchi L \& Dalla Fontana G (2008). The effectiveness of airborne LiDAR data in the recognition of channel-bed morphology. Catena, 73(3), 249-260.

Cunningham D, Grebby S, Tansey K, Gosar A \& Kastelic V (2006). Application of airborne LiDAR to mapping seismogenic faults in forested mountainous terrain, southeastern Alps, Slovenia. Geophysical Research Letters, 33(20).

Çelik H, Baş N \& Coşkun H G (2013). Taşkın Modelleme ve Risk Analizinde LiDAR Verisiyle Sayısal Yükseklik Modeli Üretimi. Gümüşhane Üniversitesi Fen Bilimleri Enstitüsü Dergisi, 4(1), 117-125.

Filin S, Baruch A, Avni Y \& Marco S (2011). Sinkhole characterization in the Dead Sea area using airborne laser scanning. Natural Hazards, 58(3), 1135-1154.

Glennie C L, Hinojosa-Corona A, Nissen E, Kusari A, Oskin M E, Arrowsmith J R \& Borsa A (2014). Optimization of legacy lidar data sets for measuring near-field earthquake displacements. Geophysical Research Letters, 41(10), 3494-3501.

Karasaka L \& Beg A A R (2021). Yersel lazer tarama yöntemi ile farklı geometrik yapıdaki özelliklerin modellenmesi. Geomatik, 6(1), 54-60.

Karasaka L \& Keleş S H (2020). CSF (Cloth simulation filtering) Algoritmasının Zemin Noktalarını Filtrelemedeki Performans Analizi. Afyon Kocatepe Üniversitesi Fen ve Mühendislik Bilimleri Dergisi, 20(2), 267-275.
Kasai M, Ikeda M, Asahina T \& Fujisawa K (2009). LiDARderived DEM evaluation of deep-seated landslides in a steep and rocky region of Japan. Geomorphology, 113(1-2), 57-69.

Kaya Y, Yiğit A Y, Ulvi A \& Yakar M (2021). Arkeolojik Alanların Dokümantasyonununda Fotogrametrik Tekniklerinin Doğruluklarının Karşılaștırmalı Analizi: Konya Yunuslar Örneği. Harita Dergisi, 165, 57-72.

Kobal M, Bertoncelj I, Pirotti F, Dakskobler I \& Kutnar L (2015). Using lidar data to analyse sinkhole characteristics relevant for understory vegetation under forest cover-Case study of a high karst area in the Dinaric Mountains. Plos one, 10(3), $\mathrm{e} 0122070$.

Makineci H B (2016). İnsansız Hava Araçları Lidar Etkileşimi. Geomatik, 1(1), 19-23.

Meigs A (2013). Active tectonics and the LiDAR revolution. Lithosphere, 5(2), 226-229.

Navruz M (2017). Airborne Lidar ve Dted2 Verilerinde Yükseklik (H) Karşılaştırması. Geomatik, 2(3), 112117.

Perroy R L, Bookhagen B, Asner G P \& Chadwick O A (2010). Comparison of gully erosion estimates using airborne and ground-based LiDAR on Santa Cruz Island, California. Geomorphology, 118(3-4), 288300.

Polat N \& Uysal M (2016). Hava Lazer Tarama Sistemi, Uygulama Alanları ve Kullanılan Yazılımlara Genel Bir Bakış. Afyon Kocatepe Üniversitesi Fen Ve Mühendislik Bilimleri Dergisi, 16(3), 679-692.

Şen A \& Bayaslı B (2021). Hava Lidar verilerinin denetimsiz yapay sinir ağları kullanılarak filtrelenmesi. Jeodezi ve Jeoinformasyon Dergisi, 8(1), 18-29.

Tepeköylü S (2016). Mobil Lidar Uygulamaları, Veri İşleme Yazılımları ve Modelleri. Geomatik, 1(1), 1-7.

Tseng C M, Lin C W, Stark C P, Liu J K, Fei L Y \& Hsieh Y C (2013). Application of a multi-temporal, LiDARderived, digital terrain model in a landslide-volume estimation. Earth Surface Processes and Landforms, 38(13), 1587-1601.

Ulvi A \& Yakar M (2014). Yersel Lazer Tarama Tekniği Kullanarak Kızkalesi'nin Nokta Bulutunun Elde Edilmesi ve Lazer Tarama Noktalarının Hassasiyet Araștırması. Harita Teknolojileri Elektronik Dergisi, 6(1), 25-36.

Yakar M, Ulvi A, Toprak A S \& Mutluoglu O (2014). Laser Scanning and Photogrammetric Evaluation of Uzuncaburç Monumental Entrance. International Journal of Applied Mathematics Electronics and Computers, 3(1), 32-36. 
Yakar M, Yılmaz H M \& Mutluoğlu Ö (2009). Hacim Hesaplamalarında Laser Tarama Ve Yersel Fotogrametrinin Kullanılması. TMMOB Harita ve Kadastro Mühendisleri Odası 12. Türkiye Harita Bilimsel ve Teknik Kurultayı.

Yakar M, Yılmaz H M \& Mutluoğlu Ö (2010). Comparative evaluation of excavation volume by TLS and total topographic station based methods. Lasers in Eng., 19, 331-345.
Zhu J, Taylor T P, Currens J C \& Crawford M M (2014). Improved Karst Sinkhole Mapping In Kentucky Using Lidar Technıques: A Pilot Study In Floyds Fork Watershed. Journal of Cave \& Karst Studies, 76(3).

(C) Author(s) 2021.

This work is distributed under https://creativecommons.org/licenses/by-sa/4.0/ 